\title{
Über Wartezimmer
}

\section{Eberhard Wolff}

PD Dr. rer. soc., Mitglied der Redaktion Medizingeschichte

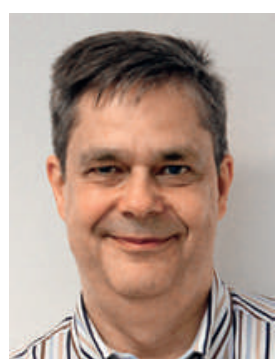

Neulich bot mich ein Spital zu einer Untersuchung auf. Worum es ging, tut wenig zur Sache. Eindrucksvoller war, dass ich eine wahrhafte WartezimmerAchterbahn durchlaufen hatte, als ich nach zwei Stunden zufrieden wieder auf der Strasse stand.

Noch bevor ich die Abteilung betreten durfte, hielt mich Warteraum 1 fest: Es war ein etwas unterkühlter Vor-vor-Wartebereich. Seine Aufgabe bestand darin, mich vor dem Passieren der mächtigen Sicherheitstüre Formulare ausfüllen zu lassen. Gleich hinter der Schleuse empfing mich Nummer 2, die gemütlichere, sesselbestückte Vor-warte-Nische. Dort klärte mich ein freundlicher Arzt über die Untersuchung und ihre Risiken auf. Die Nische half mit ihrer ruhigen, seriösen Atmosphäre tüchtig mit, dass ich die Untersuchung akzeptierte.

Als Auftakt der eigentlichen Untersuchung musste ich noch vorbehandelt werden. Bis das möglich war, testete Nummer 3 meine Belastbarkeit: eine Reihe harter Armsünder-Stühle, die peinlich im Gang vor dem Behandlungsraum standen: provisorisch, trostlos, gnadenlos öffentlich. Sie kennen sicher diese Elends-Orte, die kaum den Namen Wartebereich verdienen.

Immerhin bekam ich dadurch mit, dass etwas nicht stimmte. Dummerweise war ein Gerät defekt. Die Ersatz-Abteilung war auf wartende Zusatzpatienten aber nicht vorbereitet. Also erduldete mich dort Warteraum 4 widerwillig: Es war ein gerade ungenutztes Untersuchungszimmer. Immerhin liess es mich auf der Untersuchungsliege sitzen. Ich lernte: Der Begriff des Provisoriums kann mühelos gesteigert werden.

Nach diesen Erfahrungen versorgte mich Warteraum 5 (der letzte!) wieder mit etwas Normalität: keine provisorische Stuhlreihe. Ich hatte immerhin vier Wände um mich herum. Das war ein einigermassen versöhnlicher Übergang von der Wartezimmer-Odyssee zur eigentlichen Untersuchung.

Im kulturanthropologischen Fachchinesisch ist ein Wartezimmer ein transitorischer Raum, ein ZwischenRaum, ein Raum des Übergangs. Das hat es mit Brücken und Bahnhöfen gemein. Das Ziel der dort Anwesenden ist es, bald wieder abwesend zu sein. Aus der pragmatischen Sicht der Beschäftigten ist es ein Raum, um Patienten zwischenzuparken, damit sie nicht so sehr stören und trotzdem greifbar sind.
Wir dürfen von einem Wartezimmer nicht mehr verlangen als das, was eine störrische Architektur und die noch störrischeren Notwendigkeiten hergeben. Trotzdem bietet jeder Warteraum einen Gestaltungsspielraum. Und der verrät manchmal einiges. Ich habe das einmal anhand meiner eigenen Erfahrungen Revue passieren lassen.

Da ist etwa die moderne Spezialklinik in meiner Stadt mit ihren seriösen sesselbepackten Wartenischen. Ich fühle mich dort immer wie am Abflug-Gate B73.

Eine Gemeinschaftspraxis, die ich kenne, liegt in einer umgenutzten alten Bürgerwohnung. Das Wartezimmer ist ein Séparée, ein Einzelraum vor der Wohnungstüre, direkt vom Treppenhaus aus zugänglich. Es ist noch "draussen». Zur Behandlung muss man erst in die Wohnung/Praxis geholt werden. Den Eintritt ins "Allerheiligste» hat man hier nicht erst beim Behandlungszimmer, sondern schon an der Wohnungstüre. Die Stimmung ist hier einfach anders: unnahbarer, geheimnisvoller, aber gleichzeitig auch hochseriös.

Noch einmal anders sind Wartezimmer, deren Einrichtung an einen Kindergarten erinnert. Es gibt sie bekanntlich nicht nur bei Pädiatern. Ist das Wartezimmer hier gedacht als eine Art Wohnzimmer, als Familien- oder Generationenraum? Zumindest lebt hier mehr Alltag als anderswo.

Ein Wartezimmer, das es heute nicht mehr gibt, ist mir wegen seiner unglaublichen Deckenhöhe noch in lebendiger Erinnerung. Der Raum war einst für das Ausprobieren von Orgeln gebaut worden. Man hatte immer das Gefühl, dass nach oben alles möglich ist. Schliesslich kommt mir das Wartezimmer eines Grundversorgers in den Sinn. Es ist der architektonische Mittelpunkt und das Herz der ganzen Praxis. Ein Treffpunkt auf Augenhöhe. Hier wird alles, was nicht zwingend ins Behandlungszimmer gehört, viel offener als anderswo verhandelt. Der Arzt hat viele iberische Patienten. Hier fühle ich mich immer ein wenig wie auf einer Plaza Mayor.

Machen Sie doch selber einmal die Probe aufs Exempel. Vergleichen Sie Ihr eigenes Wartezimmer mit anderen und überlegen Sie, welcher Name passen würde. Das im Zürcher Kinderspital würde ich etwa liebevoll «Tohuwabohu» nennen. Sicher werden Sie Ihr Wartezimmer hinterher mit anderen Augen sehen [1]. 